http://dx.doi.org/10.4314/ejotmas.v7i1-2.12

\title{
JOURNALISM AS A PROFESSION: THE CHALLENGES OF WOMEN IN A DISCRIMINATORY SOCIETY
}

\author{
*Olayinka Susan OGUNDOYIN, Ph.D.
}

\begin{abstract}
Journalism is one of many professions held in high esteem. The profession, however, is not without its own challenges as women journalists find it difficult to enjoy their career in the face of issues posed by the industry. This study sought to investigate the challenges faced by women journalists in the Nigerian mediascape. It is anchored on the feminist muted group theory (FMGT). The survey research and interview methods were employed to sample 120 women journalists in some Nigerian media outfits. They were purposively selected to respond to the questionnaire and four senior women journalists based on their work experience were interviewed. Four electronic media stations (two television and two radio stations) were considered for the study. Data were analysed through simple percentages and the qualitative data analysed thematically. It was found that women journalists face myriads of challenges, including abuse, sexual harassment and marital issues such as divorce, spending inadequate time with spouse, children and participating less in family functions. In addition, some women are restricted to anchoring less challenging programmes compared to their male counterparts in the industry. Hence, it was recommended that media stations should look beyond sexual stereotyping and assist women journalists to overcome the various challenges by giving them more time to spend with their families and by giving them challenging duties that can boost their selfconfidence and help them attain enviable heights in the profession.
\end{abstract}

Keywords: Women journalists, Nigerian mediascape, Sexual stereotyping, FMGT, Challenges

\section{Introduction}

The role of women in the traditional society in Nigeria has been foregrounded not until recently when women struggled to climb up the

*Olayinka Susan OGUNDOYIN, Ph.D. is of the Department of Mass Communication, Bowen University, Iwo, Osun State, Nigeria

Email: sayogundoyin@yahoo.co.uk 
ladder of professionalism in practically every field. Right from childhood, a girl is taught how to take care of the house, her husband and become a good mother and is constantly reminded of her role and duties later in the face of failure (Oyinade, Daramola \& Lamidi, 2013). This issue cuts across cultures in Africa where the role of a woman is defined and fixed, some husbands would prefer their wives to take up jobs that would afford them the opportunity to take care of the home and pay more attention to family issues whereas some would desire them to be full house wives. It is commonly held that the first human creation was the man and it was the creation of a woman which came later because man needed companionship. This, probably, has been the genesis of the role of the woman being subordinate to a man in every stratum of society.

The saying that the role of a woman is in the kitchen began to take a new dimension in the face of the society's economic downturn that gave rise to the need for women to support their husbands. Consequently, they began to see the need to assume different positions as their male counterparts in all disciplines. This might not be in a bid to compete with them but to be relevant and recognized in the society as well. This recognition has encouraged women to take up various areas of study of which journalism is one. Before the influx of women into the profession, they were treated as consumers rather than producers of news. As women became more educated, journalism became an attractive career encouraging women to get out of their confines of domestic duties (Chambers et al., 2004).

Journalism can be described as the gathering, processing and dissemination of information conveyed as news to an audience (Niles, 2017). It could also be defined as a writing which informs the public about happenings around them, in the past, present and future. These writings can be accessed in various forms such as newspapers, magazines, television, radio, websites, etc., which have been put in place by extensive research by the journalists writing on various issues of interest. This news is densely conveyed through the broadcast and print media. The broadcast medium includes television, radio and the new media whereas the print includes newspapers and magazine. These media feed the society with information and opinions about public affairs by ensuring access to news, information and opinions that are vital features of a democratic society where the news media is not controlled by the government in power. The gathering and dissemination of information are considered to be the central role of the media that is expected to independently satisfy the public on its thirst for information and to a greater extent, adhere to journalistic principles or standards. 


\section{Women and Journalism}

Journalism was basically viewed as a profession dominated by men in the past (Okunna, 1992; Franks, 2013). As it grew, women were restricted by custom, tradition, and religion from getting into the profession and those who dared were faced with significant discrimination. In spite of this, women are not relenting in their efforts to get to the top and desired positions like their male counterparts who are editors, reporters, sport analysts and journalists. Although, the profession is deeply characterized by gender segregation with women in the minority, they are still noticeable and found to be actively involved in journalism (Chambers, Steiners \& Fleming, 2004; Lachover, 2005; Gill, 2007; Franks, 2013). Female journalists are aspiring to improve their status and to resist the culture of stereotype which has been the bane of the industry, by embracing areas that had been traditionally occupied by the male, such as hard news, crime and politics. Despite this effort, only a few of them have risen to the peak of the profession in Nigeria (Sanusi \& Adelabu, 2015). Franks (2013) claims that female journalists are more unlikely than men to achieve more senior and well-paid positions; women who do secure jobs at a senior level in journalism are more likely than men to be childless. Similarly, Neyer, Hoem and Andersson (2017) in their bid to investigate the relationship between the choice of career by women and their level of childlessness, believe that women journalists are more likely to change jobs after they become mothers.

Furthermore, Franks (2013) compared the pay gap between male and female journalists and found that there has been a great disparity in the way male journalists are paid in comparison to what the females get all over the world. This is because journalism has been observed to be organized based on masculine values notwithstanding the rise in the number of women entering the field (Ross, 2001; Melin, 2008; Löfgren-Nilsson, 2010). Historically, journalism was viewed more like an apprenticeship than attaining the professional ladder through academic qualification. This was believed to be more effective since learning informally could improve someone's practical proficiency on the job as against learning series of theoretical facts without having to spend enough time acquiring the required practical skill on the field. However, there was a shift in this trend when universities especially in the United States of America (USA) started offering courses in journalism, thereby giving young aspiring journalists the opportunity to acquire formal education training which in turn encouraged the influx of women into the industry (Bromley, 2013). Since the introduction of formal education in journalism, there has been a gradual increase in the turnout of female journalism students in USA and this trend was 
subsequently noticed in the United Kingdom and many other countries where the system was embraced (Franks, 2013). Thus, academic journalism training in USA began at the University of Missouri in 1908, when female students made up $15 \%$ of the first class. Several researches have been conducted in order to explore why women even after graduating with an appreciable number of student journalists do not enter the field in that number (Chioma, Okere, Alao, Atakiti \& Jegede, 2015; Apuke, \& Dogari, 2016). They found that women journalists were discouraged because after graduation, they do not get jobs as their male counterparts do and if they do, they find it difficult if not impossible to rise through the ranks to higher positions and consequently do not get the required representation they desire in the industry.

\section{Women, Journalism and Challenges}

Women journalists are increasingly facing a lot of challenges which is not serving as a motivation on the job. In male-dominated societies, women journalists are confronted with the challenges of religious and cultural limitations that make the notion of inequality a natural concept existing between the male and the female genders (Lachover, 2005; Gills, 2007). A woman's duty outside the home is usually viewed as inappropriate which may leave room for suspicion of infidelity especially in the area of journalism where a woman is expected to work extra hours beyond the normal working time or have to travel to spend days, weeks or even months to get some stories covered.

The path of women's entry into journalism was not a steady one as women struggled to survive in the industry despite many obstacles. In 1932, the British Broadcasting Corporation (BBC) introduced an official marriage bar which impeded women's progress as they were obliged to resign from the corporation after marriage (Murphy, 2011) whereas men still retained their jobs and positions. According to Franks' (2013) estimate, census figures in 1901 of the number of women journalists was 1, 249 which was around 9\% of the total and by 1931 , rose to 3,213 which was around $17 \%$. In 1961, the proportion of female journalists was hardly $20 \%$. This was not unconnected to the marriage bar legislation by the BBC. In other organizations, the fear that women journalists would leave work after their marriage made them not to employ women journalists in great numbers regardless of the fact that they do not have a formal marriage bar put in place in these organizations.

Franks (2013) observed that during this period, the National Union of Journalists (NUJ) had discriminatory policies on ground to discourage women from being journalists. One of such policies was 
suppressing female wages and setting a limit to the number of female journalists under training. The same attitude of discrimination against women in journalism is not limited to a particular segment but also in print and broadcast media. Women in all types of media tend to be sexualized, they make them talk less than men, seek fewer opinions from them and are deliberately excluded from occupying roles as leaders or professionals (Chambers et al., 2004). In Nigeria, the representation of women in media has been the centre of attention in recent times in media studies (Oyinade et al., 2013). Some of these studies, however, investigated how women are seen by those who set the media agenda because how women are treated can be traced to the issue of subordination of women by those who hold the control of mass media. Thus, in Nigeria and some parts of the world, the profession is mostly dominated by male (Franks, 2013; Oyinade et al., 2013). Women who remain in the industry have to fight for recognition, respect, equal opportunity and credibility (Oyinade et al., 2013).

In addition to these discriminatory acts, Franks (2013) contends that female journalists are always faced with abuse and sexual harassment. In a survey by The International News Safety Institute and the International Women's Media Foundation report cited by Franks (2013), 64 percent of female journalists around the world out of 875 women from countries across the globe reported experiencing intimidation, threats and abuse while working. These abuses were reportedly perpetrated by a boss, supervisor and even co-workers. However, these abuse and harassment are not limited to a certain period in their career but start from when these women are applying for job positions in the industry and continue as they move up in their job positions as journalists (Williams, 2015). Some other challenges are violence of a sexual nature and threat against their families, lack of prospects like their male colleagues and unfriendly maternity conditions and marriage. Most female journalists are single mothers; this is not because they do not want to keep their marriage but because of spouses who lack understanding of what journalism entails (Anyanwu, 2017).

In a war and insurgent country, women are exposed to greater risks where attacks to lives and properties are imminent. Stories that involve night club happenings, late night meetings by politicians or government officials, drug related issues, sexual reports, among others, are seen not to be within the 'jurisdiction' of a woman journalist duty since tradition and religion forbid such areas for them. Journalism is considered as a dangerous job for women especially in a violent, hostile, corrupt environment and most especially for reporters who expose injustice in violent, environment and war zones (Ronderos, 
2012). Other obstacles that pose threat to both male and female journalists include threats, murder, confiscation of materials, detention, killings, deportation, arrests and intimidation. Sexual violence is not an exception but female journalists who have been sexually assaulted have preferred to remain silent because of tradition and stigmatization that accompany it. All these are some forms of violence women journalists across the globe face in the course of discharging their duties. Ronderos (2012) reported cases of female journalists: one was Reeyot Alemu who was sentenced to 14 years imprisonment in September 2011. She was accused of conspiracy and involvement in terrorist acts and participation in a terrorist organization. She was, however, cleared from the false allegation levelled against her during her trial by presenting evidences in court about her intention to stage peaceful protests. Another case is that of a reporter for Radio Free Europe/Radio Liberty's Azerbaijani service named Khadija Ismayiova, who was framed up because she exposed corruption and power abuse at the highest levels in Azerbaijan. In May 2012, she received a threat letter which included photographs from surveillance cameras installed in her apartment in order to denigrate her. Despite these threats of defamation, Ismayilova refused to stop working. One more case deal with the murder of the Sunday Times award winning American correspondent Marie Colvin who was covering the siege of Homs in Syria among many other ugly stories. It is within this context that an attempt was made to investigate the major challenges facing women journalists in their career in Ibadan and Lagos, Nigeria.

\section{Theoretical Premise}

The study is anchored on the feminist muted group theory. The theory posits that there are certain groups of people who are silenced as they have not much power to stand and speak up for themselves. This is as a result of the mentality women carry that male are the dominant group in the society which makes female's point of view as least competent. Also, for women to be part of a society and to dominate, females must act similar to those of the dominant groups in their perception of things. Miller (2005) gave an insight into the theory by explaining that the dominant group in a society (male) controls the various avenues of expression. The theory exposes the fact that women have difficulty being accepted in and becoming part of an organization whose rules were primarily made in a male-dominated society. This theory is relevant to the challenges faced by women journalists in Nigeria. Since rules are constructed in man-made language in Nigeria, it aids in defining, depreciating and excluding women (Griffin, 2003). The theory, however, emphasizes the fact that since women have very 
little or no power to fight, they have trouble giving voice to their perception or ensuring their voice is heard which consequently has rendered female journalists in Nigeria to be muffled, overlooked and invisible.

\section{Research Method}

The research design for this study is the survey and interview. The survey was used to collect quantitative data using the questionnaire, whereas the interview was used to collect qualitative data using the interview guide. One hundred and twenty copies of the questionnaire were administered to only female journalists working in the four sampled media stations who were purposively selected. The population was selected based on the limited number of female journalists working within the various stations and some female journalists were unwilling to respond to the questionnaire. Respondents constitute females working in four electronic broadcast stations: Lagos Television (LTV) with 34 female broadcasters, Broadcasting Corporation of Oyo State (BCOS), Ibadan with 30 female broadcasters, Traffic Radio 96.1FM, Lagos with 29 female broadcasters and Federal Radio Corporation of Nigeria (FRCN), Ibadan with 25 female broadcasters. Four senior female journalists (one from each of the selected electronic media stations) were interviewed to support the data from the questionnaire.

\section{Results}

The study shows that $45.0 \%$ of the respondents were between the age ranges of $20-30$ years, $6.7 \%$ were between $51-60$ years and $3.3 \%$ above 60 years. The implication of this is that those who dominate the industry are youths who are vibrant and are still trying to make out a career for themselves. A majority of the respondents $57.5 \%$ have first degree while $0.8 \%$ has only school leaving certificate which implies that most women working in the industry are learned. A majority of the respondents are married $47.5 \%$, while $7.5 \%$ are widowed (Table 1 ). 
Table 1: Demographic characteristics of respondents

\begin{tabular}{lll}
\hline Age distribution (Years) & Frequency $(\mathrm{N})$ & Percentage \\
$20-30$ & 54 & 45.0 \\
$31-40$ & 37 & 30.8 \\
$41-50$ & 17 & 14.2 \\
$51-60$ & 8 & 6.7 \\
$>60$ & 4 & 3.3
\end{tabular}

Educational qualification

School certificate

Diploma 2

Degree 69

Marital Status

$\begin{array}{lll}\text { Single } & 42 & 35.0\end{array}$

$\begin{array}{lll}\text { Married } & 57 & 47.5\end{array}$

$\begin{array}{lll}\text { Divorced } & 12 & 10.0\end{array}$

Widowed $\quad 9 \quad 7.5$

Sixty-two (51.7\%) respondents anchor News Reporting, 58 (48.3\%) respondents each anchor women empowerment programmes, fashion and entertainment and $26(21.7 \%)$ are made to anchor Sport programme. The implication of this is that women are made to anchor female related programmes more than hard news that would rather be given to their male counterparts. The statistics of women anchoring sport programmes are relatively low in comparison to other programmes that are assigned to them (Table 2).

Table 2: Programmes anchored by the respondents

$\begin{array}{lll}\text { Programmes } & \text { Frequency (N) } & \text { Percentages } \\ \text { Women Empowerment } & 58 & 48.3 \\ \text { News Reporting } & 62 & 51.7 \\ \text { Fashion } & 58 & 48.3 \\ \text { Entertainment } & 58 & 48.3 \\ \text { Educational } & 48 & 40.0 \\ \text { Sport } & 26 & 21.7\end{array}$


Political influence and bribery were the most common challenges faced by journalists in general, observed in $50(41.7 \%)$ respondents respectively. This is followed by arson in $31(25.8 \%)$ and kidnapping is the least in $10(8.3 \%)$ of the respondents (Table 3$)$. This shows that the profession is fraught with terrible challenges that can affect the lives and careers of the practitioners.

Table 3: General Challenges of Journalists

$\begin{array}{lll}\text { Challenges } & \text { Frequency }(\mathbf{N}) & \text { Percentages } \\ \text { Kidnapping } & 10 & 8.3 \\ \begin{array}{l}\text { Beating } \\ \text { Arson (Destruction of broad- }\end{array} & 16 & 13.3 \\ \text { cast materials) } & 31 & \\ \text { Bribery and corruption } & 50 & 25.8 \\ \text { Political influence } & 50 & 41.7 \\ \end{array}$

Of the personal challenges facing female journalists, sexual harassment constitutes a major challenge with 45(37.5\%) respondents, whereas cultural and religious limitations were the least (20.0\%). The implication is that it cripples their desire to work wholeheartedly and fearlessly (Table 4).

Table 4: Personal challenges faced as a female journalist

$\begin{array}{lll}\text { Challenges } & \text { Frequency (N) } & \text { Percentages } \\ \text { Sexual harassment } & 45 & 37.5 \\ \text { Cultural and religious limitations } & 24 & 20.0 \\ \text { Family issues and challenges } & 39 & 32.5 \\ \text { Sexism } & 32 & 26.7\end{array}$

A review of the impact of journalism profession on the family lives of women journalists shows that $46(38.6 \%)$ are not able to spend quality time with their children, $44(36.7 \%)$ have frequent quarrels with their spouses, $43(35.8 \%)$ go late to work and $16(13.3 \%$ are accused of infidelity by their husbands (Table 5). The implication of this, however, is that the profession does not leave room for enough time to spend quality time with their families, their marriages may be destroyed and their efficiency at work is also affected. 
Table 5: Impact of journalism profession on the respondents' family life

\begin{tabular}{|c|c|c|}
\hline Impact & Frequency (N) & Percentages \\
\hline Inability to find a life partner & 15 & 12.5 \\
\hline Frequent quarrel with your spouse & 44 & 36.7 \\
\hline Divorce & 10 & 8.3 \\
\hline Infidelity & 16 & 13.3 \\
\hline Spending little time with the children & 46 & 38.3 \\
\hline $\begin{array}{l}\text { Too busy to know what is } \\
\text { happening to the children }\end{array}$ & 25 & 20.8 \\
\hline $\begin{array}{l}\text { Inadequate care about the } \\
\text { academics of the children }\end{array}$ & 42 & 35.0 \\
\hline $\begin{array}{l}\text { Inadequate care about the health of th } \\
\text { children }\end{array}$ & 21 & 17.5 \\
\hline Inability to meet up with deadlines & 31 & 25.8 \\
\hline $\begin{array}{l}\text { Missing meetings and seminars due } \\
\text { to family issues }\end{array}$ & 30 & 25.0 \\
\hline Lateness to work or cover story & 43 & 35.8 \\
\hline $\begin{array}{l}\text { Rejection of certain positions in the } \\
\text { organization because of family }\end{array}$ & 35 & 29.2 \\
\hline
\end{tabular}

In maintaining balance between their career and family life, 31 (25.8\%) strongly agreed that they find it difficult. This shows that a substantial number of these women in the industry are facing some form of problems in their homes because of the nature of their work (Table 6).

Table 6: Female journalists find it difficult to maintain balance between their career and family

\section{Responses}

Agree

Strongly agree

Undecided

Disagree

Strongly disagree

Total

\section{Frequency (N) Percentages}

28

31

23.3

25.8

35.0

10.8

$6 \quad 5.0$

120 100.0 


\section{Discussion}

The various programmes anchored by the women journalists as highlighted in this study have been said to have been specifically reserved for them. This is ostensibly because it is assumed that they can handle the programmes successfully (Ekeoba, 2015) since it falls within the confines of their traditional role at the home front. The responses from the interview indicated that there is a stable progress in the number and contribution of women journalists which has tremendously added to the growth of the media. Improvements have been noted from the initial traditional role of women through to their contribution to children and women affairs, fashion, gossip column, food, culture beats and education, despite this, some women journalists have grown to become editors and publishers. This agrees with a similar study by Chambers et al. (2004) that reported that women journalists are aspiring to improve their status by embracing areas that had been dominantly occupied by their male counterparts such as hard news, crime and politics.

An attempt was made to investigate the general challenges of journalists. In this regard, respondents believe that bribery and corruption with political influence were the commonest challenges journalists face in general. Journalists are faced with a serious dilemma of either to collect bribe, cover a particular story that is favourable to the concerned party as against what actually obtains, or give bribe in order to get the desired information by getting people to volunteer the information. Also, political influence is a challenge because in politics, those who have the upper hand can influence the journalistic process put in place. That is why press independence is often advocated. This act of political influence is not unconnected with the fact that the ruling party would always want to remain popular in the eyes of the populace, hence, would want to filter or monitor what information is disseminated to the general public. Some other respondents believed that journalists are faced with kidnapping, assault and destruction of broadcast materials; these are findings that agreed with Ronderos (2012) who claims that the obstacles both male and female journalists face include threats, murder, confiscation of materials, detention, killings, arrests, intimidation, etc.

The study examined the impact of the profession on the respondents' family life and the findings corroborated the report of Chambers et al (2004) that women in all types of media tend to be excluded from occupying roles as leaders or professionalsbecause of the negative impact on their families and the fact that the women may be less efficient in their professional duties in a bid to manage their homes together with their profession. The respondents interviewed argued that existing cultural biases deny both male and female equal 
opportunities. This is because the concept of gender comes with undisputable specified roles, when women violate traditional gender norms by exhibiting a degree of equality with men in some areas like decision making or playing leadership role, they are perceived to beirresponsible and too ambitious. However, one of the interviewed respondents expressed her displeasure on the challenges some women face in their family. A brief narration about the unpleasant experience of a colleague was cited as an example, who became a single mother because of the demand of her job and her effort to get resettled has been abortive. Another point in case is the challenge of some women journalists' inability to conceive not because of any prominent medical condition but because they are always unavailable to attend and expand their family lineage (Franks, 2013). This set of women are usually found at the top management level, while busy building their career, they overlook the issue of marriage as well as planning their family. She expressed bitterness on how the system is not encouraging this pathetic situation, because they observe that most women are taken away from the various programmes they anchor to a less challenging ones the moment they become pregnant.

The findings on the personal challenges faced by women journalists are many, some of which are sexual harassment which is commonly reported by women journalists. This corroborates the studies conducted by Franks (2013) and Ronderos (2012) which stated that women journalists all over the world are faced with the issue of sexual harassment. Another challenge they face is family issues and challenges which may have a strong connection to cultural and religious limitations. It is a well- known fact that both culture and religion have rules that women within the society must abide by which women in journalism may contravene because of the demand of the industry. When this happens, it tells more on the family and the religious institution the person is affiliated to. Lastly sexism is part of the challenges identified. These women claimed that they are exposed to sexism where partiality brews in favour of their male counterparts. This can be seen in their role as leaders, decision makers, pay, reward and programmes they anchor. The response from the interview revealed that women have less access to key decision-making positions in media organizations because they tend to get violent resistance from their male counterparts who feel women are in subordination to men in all spheres.

The problem, however, is that a majority of the male journalists have difficulty accepting the editorship of women which has an impact on the numbers of female leaders emerging in the newsroom (Anyanwu, 2017). Thus, the finding is in line with the study of Franks (2013) who observed that women who have reached senior positions 
or high level of career success are always suspected to have at one time offered themselves for sex, flirted or flaunted themselves in order to obtain a story to compromise their expertise. The responses from the interview overwhelmingly showed that women journalists face many types of professional challenges. Some of which are: late night work, sexual abuse, job insecurity, motherhood and domestic issues, gender discrimination, low reward system and low job satisfaction. In addition, the interview responses further claimed that women journalists are constantly sexually harassed. This type of harassment is common among a superior male boss and female subordinate, while the other category is getting sexually harassed by stakeholders in possession of the needed information (McLaughlin, Uggen \& Blackstone, 2012). Findings of the study show that women journalists are working hard to maintain a balance between their homes and profession despite the challenges faced at the home front. The response from the interview revealed that many women journalists are striving hard to keep their homes in spite of their busy schedules and at the same time working hard in order to be professionally relevant. An undisclosed source revealed that some women still remain in their marriage even after it had turned abusive because they do not want to be stigmatized by the society.

\section{Conclusion}

The challenge of threats to life and family that journalism as a profession poses to women journalists is not peculiar to the Nigerian mediascape but to all practicing women journalists around the globe. The peculiarity of the profession has ruined some homes, while some suffer stigmatization. Media organizations should, however, look beyond sexual stereotyping and help women journalists to overcome the various challenges by giving them more time to spend with their families as well as giving them challenging duties that can boost their self-confidence and help them attain enviable heights in the profession.

\section{References}

Anyanwu, C. (2012). In Nigerian newspapers, women are seen, not heard. Retrieved 1 January 2019, from https:// niemanreports.org/articles/in-nigerian-newspapers-womenare-seen-not-heard/.

Apuke, O \& Dogari, K. (2016). The attitude of mass communication students towards journalism as a career at Taraba State University, Jalingo, Nigeria. Retrieved 10 November 2019, fromhttps://www.researchgate.net/publication/ 317142425 The Attitude of female mass communication students. 
Bromley, M.S. (2013). The 'new majority' and the academization of journalism. Journalism, 14(5), 569-586.

Chambers, D. et al. (2004).Woman and journalism. London: Routledge.

Chioma, P., Okere, S., Alao, O., Atakiti, I., \& Jegede, O.(2015). Career considerations in journalism among female mass communication students of Redeemers University. International Journal of Humanities and Social Sciences, 5(14), 2225-0484.

Ekeoba, P. (2015). Media and masculinities: The role of media outlets in Nigeria in shaping perceptions of masculinities. AUkaud report on voices4change, Empowering Adolescent girls and women in Nigeria. Retrieved 31 December 2018, from

https://www.ces,uc.pt/myces/UserFiles/livros/ 1097 V4C Media andMasculinities Report July 2015\%(20).pdf.

Franks, S. (2013). Women and journalism. London: I.B Tauris \& Co Ltd.

Gill, R. (2007). Gender and the media. Cambridge, MA: Polity Press.

Griffin, E. (2003). A first look at communication theory $\left(5^{\text {th }} e d\right)$. Boston, MA: McGraw-Hill.

Lachover, E. (2005). The gendered and sexualized relationship between Israeli women journalists and their male sources. Journalism, 6(3), 291-311.

Löfgren-Nilsson, M. (2010). "Thinkings" and "doings" of gender: Gendering processes in Swedish television news production. Journalism Practice, 4(1), 1-16.

McLaughlin, H, Uggen, C \& Blackstone, A. (2012). Sexual harassment, workplace authority and the paradox of power. American Sociological Review, 77(4), 625-647.

Melin, M. (2008). Gendered newsroom cultures: Strategies and tactics in the field of journalism in Britain and Sweden. Doctoral dissertation, Department of Journalism and Mass Communication, University of Göteborg.

Miller, K. (2005). Communication theories: Perspectives, processes, and contexts. New York: McGraw-Hill.

Murphy, K. (2014). A marriage bar of convenience? The BBC and married women's work 1923-39. Twentieth Century British History, 25(4), 533-561.

Niles, R (2017). What is Journalism? Retrieved 14 September 2018, from https://www.robertniles.com/journalism.

Okunna, S (1992). Female faculty in journalism education in Nigeria: Implications for the status of women in the society. Africa Media Review, 6(1), 47-58. 
Oyinade, R.B., Daramola, I. Lamidi, I (2013). Media, gender and conflict: The problem of eradicating stereotyping of women in Nigeria. Singaporean Journal of Business Economics and Management Studies, 2(1), 27-41.

Ronderos, K (2012). Women journalists in the eye of the storm. Association for Women's Rights in Development. Retrieved 30 November 2015, from http://awid.org/eng/News-Analysis/ Friday-Files/Women-Journalists-in-the-eye-of-the-storm.

Ross, K. (2001). Women at work: Journalism as en-gendered practice. Journalism Studies, 2 (4), 531-544.

Tumber, H. (2006). The fear of living dangerously: Journalists whore port on conflict. International Relations, 20(4), 439-451.

Neyer, G., Hoem, J., Andersson, G. (2017). Education and childlessness: The influence of educational field and educational level on childlessness among Swedish and Austrian women. Retrieved 10 October 2019, from https://link.springer.com/chapter/10.1007/978-3-31944667-7_9.

Sanusi, B.O. \& Adelabu O.T (2015). Women in journalism practices in Nigeria: From the hood to the limelight. Journal of Research and Development, 2(6), 1-7.

Williams, B. (2015). Female journalist and harassment. Retrieved 15 December 2018, from https://medium.com/thoughts.on.

Wolfe, L (2011). The silencing crime: sexual violence and journalists. Retrieved 20 September, 2015, from http://cpj.org/reports/ 2011/06/silencing-crime-sexual-violence-journalists.php> . (2017). Our Challenges on the job by female journalists. The Nation, November 11, 2017. Retrieved 31 December 2018, from https://thenationonlineng.net/challenges-jobfemale-journalists/ 